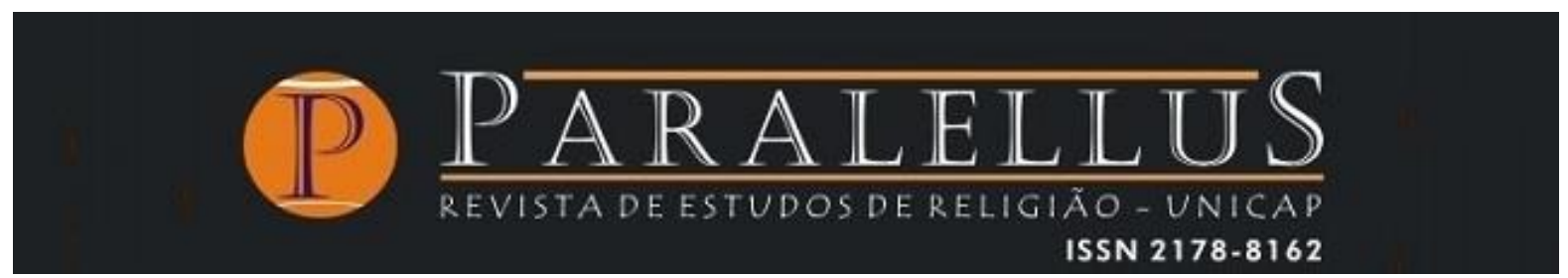

Volume 12 - Número 30

DOSSIÊ: A SABEDORIA NAS SAGRADAS ESCRITURAS

doi: 10.25247/paralellus.2021.v12n30.p399-413

\title{
DIANTE DA POLÍTICA OPRESSORA, OS CORPOS DOS ENAMORADOS ACENAM REBELIÕES (CT 6,4 - 7,10)
}

\author{
BEFORE THE OPPRESSIVE POLICY, THE BODIES OF THE ENMORADO \\ WAVE REBELLIONS (CT 6,4 - 7,10)
}

Antonio Carlos Frizzo*

\section{Resumo}

Na hermenêutica bíblica, compreendida por "leitura descolonizadora", verifica-se que o projeto de volta a Sião, na época pós-exílica (538 a.C.), durante o Império Persa, tão bem justificado nos livros de Neemias e Esdras, legitima, sim, um projeto contra pequenas experiências tribais, afronta culturas e corpos da parte de um império que durou por mais de dois séculos. Eis o objetivo do artigo que tem no poema do livro dos Cânticos dos Cânticos $(6,4-7,10)$, sua análise bíblica para desconstruir ideologias e práticas dominadoras.

Palavras chaves: Império Persa, Neemias, Esdras, teocracia, Cântico dos Cânticos.

\section{ABSTRACT}

In the biblical hermeneutics understood by "decolonizing reading", we see that the project of returning to Zion, in the post-exilic era, during the Persian Empire, narrated in the books of Nehemiah and Ezra, legitimates a project against small tribal experiences, affronts cultures and bodies to legitimize an empire that lasted over two centuries. This is the aim of the article that finds in the narrative of the fifth poem, in the book of Song of Songs (6:4-7:10), the biblical analysis to deconstruct dominating ideologies and practices.

Key-words: Persian Empire, Nehemiah, Ezra, theocracy, Song of Songs.

\footnotetext{
" Possui doutorado em Teologia Bíblica pela Pontifícia Universidade Católica do Rio de Janeiro (2009). Atualmente é professor na Faculdade Católica de São José dos Campos e no ITESP, São Paulo.
}

Paralellus, Recife, v. 12, n. 30, mai./ago. 2021, p. 399-413 


\section{INTRODUÇÃO}

George Floyd foi assassinado no dia 25 de maio de 2020, na cidade de Minneapolis, após ter sido retirado de dentro do seu automóvel. O policial Derek Chauvin conseguiu imobilizá-lo e, por sete minutos e quarenta e seis segundos, ajoelhou-se sobre o pescoço de Floyd, sufocando-o, apesar dos suspiros audíveis que repetidamente exclamava "eu não consigo respirar", causando sua morte. O episódio motivou uma comoção social em todos os estados americanos. Ecoou mundo afora, motivando inúmeras manifestações em defesa dos direitos humanos e reivindicações históricas dos negros americanos. Julgado, o policial pôde ver confirmada sua pena a 40 anos de reclusão.

Na manhã de 6 de maio de 2021, o batalhão da Polícia Civil ocupa a favela localizada no bairro do Jacarezinho, zona Norte, na cidade do Rio de Janeiro, resultando na morte de 27 moradores e um agente da polícia. Apesar do Supremo Tribunal Federal (STF) ter emitido parecer proibindo ações militares nas favelas em tempos de pandemia. Perguntados, os moradores denunciaram reiteradas execuções. Pessoas, após se entregarem à polícia, foram alvejadas a queima roupa, dentro de suas casas, diante de suas esposas e filhos. As vítimas tinham entre 18 e 43 anos. De um grupo com 21 suspeitos por estarem ligados ao tráfico, apenas três já tinham recebido mandados de prisão. Fica evidente que nessa linha abaixo do Equador, a violência sistêmica contra negros, pobres, meninas e meninos periféricos segue, entre velhas ou novas estratégias, a triste marca de um racismo estrutural. Para o delegado Roberto Cardoso, a ação foi justa, diante da morte do policial André Frias, alvejado no início da operação. O Ministério Público do Rio de Janeiro (MP-RJ) acena o desejo de investigar a chacina. Segundo Cláudio Castro, governador recém-empossado, disse ser legítima a operação e que não houve abuso por parte da polícia. Já, para o vicepresidente do país, Hamilton Mourão, general da reserva, a equação é bem mais simples de ser compreendida: "eram todos bandidos". 
O que há em comum entre as ações repressivas, seja na cidade de Minneapolis ou na favela de Jacarezinho, são corpos vitimados por agentes policiais que deveriam ampará-los e protegê-los. Mortos por serem negros e pobres. Para esses grupos não há pena de morte, mas morte sem pena (BRITO, 2018, p. 190).

O artigo observa nos corpos dos enamorados, centrado no quinto poema do livro Cântico dos Cânticos, um legítimo movimento de reviravolta frente ao modelo teocrático que se instalou na Yehud - nome dado à província de Judá no período persa - oficialmente exposto nas narrativas dos livros de Neemias e Esdras. Verifica-se a existência de uma oposição ao modelo da teocracia com base no sexto poema do livro dos Cântico dos Cânticos (Ct 6,4-7,10).

\section{O SURGIMENTO DE UMA TEOCRACIA SOB OS INTERESSES PERSAS}

Nas leituras dos livros históricos, apesar do elevado desejo de reconstrução de Yehud, o leitor se depara com narrativas ingênuas, anacrônicas e radicalmente defensoras da teologia oficial, de cunho sacerdotal impostas pelo grupo responsável pela redação final das obras. Há um esforço de compreender o universo da literatura bíblica em diálogo com os resultados das pesquisas arqueológicas. Essa interdisciplinaridade tem favorecido ler e compreender os diversos ambientes sociais, as disputas ideológicas e os interesses no controle do poder espelhados nas narrativas bíblicas (FRIZZO, 2020, p 208). Compreende-se, nesse sentido, que o livro de Neemias registra a triste notícia oriunda de Jerusalém que o fez "sentar, chorar e ficar de luto vários dias, jejuando e rezando ao Deus do céu" (Ne 1,4), pelo vexatório estado de abandono que se encontra Jerusalém. A notícia o faz se aproximar do rei e expor seus desejos de regresso a Judá. O ex-copeiro passa a ser líder político. Surge, assim, o que compreende-se como uma história oficial da comunidade religiosa que opta por voltar e reconstruir, não só uma cidade - Jerusalém - como toda sua antiga tradição religiosa.

Tem início uma fase emblemática que definirá o futuro da comunidade religiosa nos próximos séculos, pois no cenário político, Judá nunca provará experiências de um estado livre e soberano, como nos anos que antecederam a ocupação babilônica, nos anos 597 a.C. Aos olhos das políticas persas o ufanismo literário esconderá o forte 
jugo tributário exigido pelos governantes persas. A elite judaita, em seu retorno a Sião, não ensaiará um mínimo de esforço para se opor aos projetos da corte persa aplicados à região. Acredita-se que fortalecer Judá torna-se parte de um projeto de elevada estratégia militar e interesses de controle nas fronteiras do Sul da Palestina.

Ao percorrer cerca de 1.330 quilômetros - distância de Babel a Jerusalém - e entregar as credenciais reais "aos sátrapas e aos governadores da Transeufratênia, aos quais deram seu apoio ao povo e ao Templo de Deus", (Esd 8,36), a redação final do livro realça poderes ilimitados exercidos por Esdras. As narrativas bíblicas não identifiquem qual Artaxerxes referência, se é do I ou II, o que dificulta a precisão histórica dos fatos, mas uma ordem real é posta nas mãos de Esdras (Esd 7,11-26) e nela três metas são realçadas:

1 Permissão para que os judeus residentes em Babilônia regressem para Jerusalém. Usufruindo-se dos trabalhos realizados por Zorobabel, já com o templo consagrado em 515 a.C. as famílias sacerdotais regressam. O editor final não se esquiva de revelar seu total entusiasmo com a subida a Jerusalém de importantes grupos de famílias, todas ligadas a uma linhagem sacerdotal (cf. Esd 8);

2 Elevação da Lei de Moisés à categoria de lei do Estado - obrigatória para todas as pessoas. O credenciamento de Esdras e sua autoridade absoluta estão centrados em seu zelo pela Lei de Deus e na tarefa de ajustar este ordenamento jurídico à vontade da Lei do Rei. O texto insiste no equilíbrio de um Esdras centrado no conhecimento da Lei de Moisés e a proteção de Javé. Ao redor de Esdras concentram-se as funções de sacerdote e de um versado escriba (cf. Esd 7,6);

3 Indicação de um elevado recurso financeiro à disposição de Esdras, com a finalidade de organizar e embelezar o culto javista no templo de Jerusalém. A soma significativa de bens - prata, ouro, utensílios e oferendas (Esd 8,25-27) - revela o nível de envolvimento e interesse da corte persa no projeto de repovoamento da região.

Sobre a liderança de Esdras, exposta no livro, nota-se uma significativa movimentação religiosa no desejo de que, em sua condição emblemática de representante da realeza, construa uma redoma, um cerco ao redor da Lei, por parte dos grupos sacerdotais representados em sua figura. Protegê-la com todo ardor e zelo é a ênfase do redator final, ao exaltar suas qualidades: “... este Esdras subiu de Babilônia. Era um escriba versado na Lei de Moisés, dada por lahweh, o Deus de Israel” (Esd 7,6). Tal imagem de guardião o autoriza a ler publicamente um conjunto de textos, oriundos 
da Babilônia, redigidos por grupos de sacerdotes, de levitas e de cantores, que por quase duas gerações haviam celebrado, lido e refeito valores religiosos da época préexílica. Formataram antigos e novos ensaios teológicos sobre a divindade máxima Javé. Revisitaram o mito da criação, a tese de Israel na condição de povo eleito por uma divindade exclusiva; condutas éticas e regras de convivências sociais. Tal conjunto de narrativas são apresentadas no projeto de inaugurar uma teocracia. Ousa estabelecer o predomínio da tradição sacerdotal e a desqualificação étnica dos pobres da terra - grupos de trabalhadores remanescentes da guerra que receberam terras e delas cuidaram após a guerra de 587 a.C. (2Rs 25,22-24). A centralidade de toda vida social teve Jerusalém como a cidade santa, sede do templo, a morada de uma divindade que passa a ser cultuada como única e universal (cf. Dt 6,4-9). Este conjunto de leis é determinante e enaltecido pelo narrador final nas atitudes de Neemias e Esdras.

O processo de compilação dessas narrativas, realizado por volta do ano 400, foi intitulado de Pentateuco, resultado de um processo redacional que compilou um conjunto relativos de textos já conhecidos, nos diferentes grupos sacerdotais, por diferentes nomes: "Lei de Moisés" (Esd 7,3), "Leis do Deus dos céus" (Esd 7,21) ou "Lei do teu Deus" (Esd 7,26) e, igualar a Lei divina como "lei do rei" (cf. Esd 7,26), foi uma, entre tantas iniciativas, de impor o projeto sadoquita que triunfou.

A leitura e promulgação da Lei de Moisés parecem ter sido usadas como um bom antídoto no desejo de selar a paz entre diferentes famílias sacerdotais as quais aderiram ao projeto da volta a Sião. Uma vez com os pés na terra, foi essencial certa harmonia entre os grupos sacerdotais e levitas na necessidade de encontrar forças no movimento contra grupos contrários ao projeto de reedificação da cidade de Jerusalém. Não se pode ignorar a resistência dos samaritanos, muito menos, possíveis desacordos com o "povo da terra". Nada impede de verificar que esse último grupo residisse nas vilas localizadas na região de Benjamin, contrários às reformas e aos ideais dos grupos repatriados.

Embora os registros literários tenham sido concluídos em época posterior às datas indicadas, percebe-se uma orquestrada narrativa desejosa de implementar, aperfeiçoar e perpetuar a ideia de que Judá é meramente parte de uma satrapia e, 
como tal, deve se compor e responder aos interesses do império que planejou, financiou e passa a controlar sua organização (GERSTENBERGER, 2014, p. 169).

Na pessoa de Neemias, opta-se por ver um personagem que, aos olhos dos que subiam à cidade de Sião - o grupo da golah - era tido como modelo de cidadão. Aliados aos seus desejos de restaurar a cidade de Jerusalém, o templo e seus espaços administrativos, vê-se um Neemias engrandecido pelos redatores finais do livro que recebe seu nome. Em nada, este ex-copeiro, desabona sua divindade e conterrâneos. Para alguns, um político piedoso; para outros, um político ingênuo; aos mais críticos, um político astuto; e, na visão da maioria, um agente político sensível. Há um exagerado esforço literário em aceitar e aprovar todas as ações idealizadas por esse governador da província de Yehud (ROSSI, 2020, p. 375).

O autor final exalta o teor da hostilidade praticada por Neemias. Todas as normas de comportamento ético, religioso e social, tem como critério a leitura do livro de Moisés (Ne 13,1). Ao tomar conhecimento das uniões matrimonias e de que certos jovens já não falavam o idioma hebreu ( $\mathrm{Ne}$ 13,23-24), o líder teve a iniciativa de "discutir", "lançar maldições" sobre os confrades, "bater", "arrancar os cabelos" e "prestar juramento" em nome de "Elohim" de que ninguém na comunidade religiosa deveria

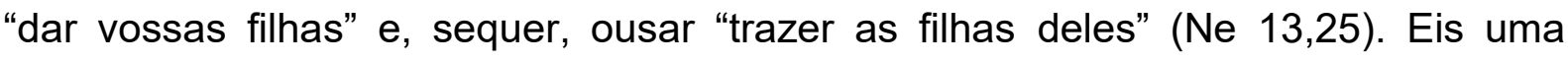
imposição repleta de requintes violentos e étnicos, com fortes interesses econômicos irrefutáveis:

Naqueles dias também, encontrei judeus que se tinham casado com
mulheres azotitas, amonitas ou moabitas. Quanto a seus filhos, a
metade falava a língua de Azoto ou a língua deste ou daquele povo,
mas não mais sabia falar a língua dos judeus. Admoestei-os e
amaldiçoei-os e bati em diversos, arranquei-lhes os cabelos e ordenei-
lhes, em nome de Deus: "Não deveis dar vossas filhas aos filhos deles,
nem tomar como esposas para vossos filhos ou para vós mesmos,
algumas filhas deles! (Ne 13,23-25).

Sem margem de dúvida, a lei da pureza étnica constituirá uma jurisprudência, na medida em que, na direção e controle das políticas implementadas na província, grupos sacerdotais passem a representar, em suas funções, os poderes do monarca. Grande número de homens - ricos ou não - estava, segundo as ideias de uma teocracia, impuros e foram obrigados a separarem ou abandonarem casamentos com mulheres estrangeiras. Forma-se um novo estatuto administrativo. Pela narrativa, não 
se sabe o final dos projetos de Esdras. O livro termina durante o andamento de sua reforma. As últimas datas de suas memórias referem-se ao vigésimo dia do nono mês do sétimo ano de Artaxerxes (Esd 10,9.16-17). A lei da pureza étnica tomou corpo, na medida em que, na direção e controle das políticas implementadas na província, grupos sacerdotais passaram a representar, em suas funções, os poderes do monarca.

Após a leitura solene da Lei de Moisés, Esdras segue enfrentando o problema dos casamentos mistos (Esd 9-10), tema não solucionado por Neemias e que persistira em sua época (Ne 13). É possível verificar que o projeto de imposição e normatização das relações afetivas será fortemente criticado. Um bom exemplo é a máxima exposta pelos poetas e poetisas, compiladores do livro Cânticos dos Cânticos: o "amor é tão forte como a morte", e nada e ninguém tem meios ou poderes de impedi-lo que se manifeste e aconteça (Ct 8,6).

\section{UMA PROFECIA SAPIENCIAL NA REBELIÃO DOS CORPOS ENAMORADOS}

A literatura de estilo sapiencial expõe um considerável estilo profético. Se ousam oficializar a proibição dos casamentos mistos, segregar puros de impuros, como foi tão arduamente defendida nos planos de Neemias ( $\mathrm{Ne} \mathrm{9,2;} \mathrm{5,17-19;} \mathrm{13,25-27)} \mathrm{e}$ Esdras (Esd 1,2-4; 4,4-5; 9,1-3.11-12), na visão de Cântico dos Cânticos ocorre uma dissonância. Não há forças que possam submeter o amor às ordens estabelecidas. Em outras palavras, o poder religioso de uma elite sacerdotal teve inúmeros meios para controlar o relacionamento social das famílias, mas não teve os mesmos instrumentos para monitorar o amor entre dois jovens enamorados (Ct. 1,7; 3,1-2; 4,15; 6,5-7). Trata-se de construir e restaurar a tese de um povo de irmãos que não vive na servidão e muito menos oprime seus irmãos. Toda a beleza e o infinito mistério do amor, responsável pela união das pessoas e seus corpos, se opõem às normas rígidas e preestabelecidas pelas leis oficiais da teocracia.

Nos oito capítulos que formam o livro, ecoa a primazia absoluta do amor. $\mathrm{Na}$ expressão ahavah, termo hebraico, traduzido por amor, surge seis vezes (Ct 2,4; 2,5; $3,10 ; 5,8 ; 7,7 ; 8,6)$, em quatro poemas. O assunto entre os jovens não era casamento ou uma união estável, mas, simplesmente, o amor. Eram jovens livres e plenamente 
dispostos a estarem com o "amado de sua alma" $(1,7)$. Jovens que se negavam a fechar o amor em normas estabelecidas pelo regime patriarcal. Não aceitavam casamentos acordados pelos pais. Ser livre e manter-se plenamente livre era o desejo dos enamorados e, o amor é compreendido como força de origem divina e ninguém pode controlá-lo ou ousar impedi-lo de se manifestar.

A estrutura imposta ao quinto poema (Ct 6,4-8,4) realça a formosura da amada. $A$ frase introdutória: "És bonita, minha amiga" (Ct 6,4) encontra eco na primeira indicação topográfica recorda a cidade de Tersa, sede das realezas de Jeroboão, Baasa, Ela, Zambri e, finalmente, Amri (1Rs 14,17; 15,21; 16,8; 16,15 e 16,23). Após esse último, a capital será implementada na Samaria, deixando Tersa de ser capital do reino do Norte. Para as poetisas e poetas, autores dos Cânticos, a lembrança de Tersa justifica-se no desejo de valorizar os moradores autóctones que passaram a residir na região após a ocupação assíria (2Rs 17,24). Vê nesta abertura uma tentativa radical de suplantar os projetos segregacionistas imposto pelo governante Neemias (Ne 13,23-27).

Jerusalém é a cidade compreendida como "formosa" (Ct 6,4). A cidade, vista em todo o seu enquadramento arquitetônico, demonstra ser um lugar seguro e pronta para receber, sem distinção alguma, moradores de todas as nações. É a cidade escolhida para o encontro dos enamorados. A tradicional cidade encontra-se reconstruída para abrigar todas as pessoas, sem qualquer distinção étnica. Nela, não mais se verá as marcas das destruições provocadas pela guerra, como bem ecoa a narrativa do terceiro livro do profeta Isaías: "Como um jovem desposa uma virgem, assim te desposará o teu edificador. Como alegria do noivo pela sua noiva, tal será a alegria que o teu Deus sentirá de ti. Sobre teus muros, ó Jerusalém, postei guardas; eles não se calarão nem de dia nem de noite" (Is 62,5-6).

Segue a citação da atual capital Jerusalém, declarada "formosa" por seu conjunto arquitetônico e A beleza se encarna numa jovem chamada Sulamita. "Retorna Sulamita, retorna; volta-te, volta-te para que possamos contemplar-te! Que olhais na Sulamita...como dança entre dois pelotões?" (Ct 7,1-2). A quem representa Sulamita? Provavelmente, a jovem Sulamita é a representação da comunidade de Judá no período em que as lideranças religiosas, as famílias, os grupos de pensadores e 
pensadoras, as profetisas e profetas regressam da Babilônia. Babilônia significa, em toda a bíblia, os quarenta anos vividos no exílio.

É mais simples ver nela o nome de uma jovem que protesta e reage diante da manipulação da mulher e do ser humano. Esse nome pode identificar todas aquelas que são "feitas rainhas", amantes de ricos marajás, e enquanto servem aos seus caprichos dos que as pagam, são "rainhas"; depois voltam, de onde partiram, a um estágio de miséria humana inferior (MAZZAROLO, 2000, p. 194).

As ideias de uma nação unificada podem ser comprovadas nos diálogos entre os enamorados, no sexto poema $($ Ct 6,4-7,10). A experiência dos repatriados se soma à vivência dos demais grupos que permaneceram na província de Judá. Oportuno percorrer todo o poema:

Ele.

6,4 És formosa, minha amiga, como Tersa, encantadora como Jerusalém, esplêndida como as constelações.

5 Aparta de mim teus olhos, porque eles me perturbam!

Teus cabelos são como um rebanho de cabras, esparramando-se pelas encostas de Galaad.

6 Teus dentes são como um rebanho de ovelhas, recém-saídas do lavadouro; cada um com seu par, sem perda alguma.

7 Tuas faces são metades de romã, na transparência do véu.

Os quatro primeiros versículos formam o primeiro canto $(6,4-7)$, dos outros três que formam o sexto poema $(6,8-12 ; 7,1-6 ; 7,7-10)$. As figuras de linguagem não deixam dúvidas da troca de afeto entre o amado e sua amada. A descrição da amada exige um olhar atento ao corpo que possibilitará pressupostos imaginativos, segundo a cultura semita. Na prerrogativa do corpo repousa a base para o conhecimento. $O$ olhar é envolvente e tem a capacidade de possuir o coração, a vida do amado (cf. Ct 4,9). Trata-se de um olhar que não afasta e, muito menos, provoca medo diante do desconhecido. Todos os elementos que formam o rosto - cabelos, dentes e faces - 
recebem comparações com elementos da natureza expressando fartura, riqueza e intimidade.

Por se tratar de um recurso de linguagem poético e não de um gênero literário narrativo, fica evidente a possibilidade múltipla de inúmeras "Galaads". Galaad se transforma no lugar onde se ama, onde há segurança e paz para o encontro dos enamorados. A Galaad bíblica está situada diante da cidade de Bet-Shean, à margem direita do rio Jordão, com um conjunto de montanhas e planaltos bem irrigados mantendo suas terras sempre férteis. Uma forte referência ao poderio econômico da cidade pode ser comprovada em Gn 37,25: "Erguendo os olhos, eis que viram uma caravana de ismaelitas que vinha de Galaad. Seus camelos estavam carregados de alcatira, de bálsamo e ládano que levavam para o Egito".

Ele.

8 Sessenta são as rainhas, oitenta as concubinas, além de numerosas donzelas.

9 Uma só, porém, é a minha pomba, o meu primor:

única é ela para sua mãe, é o encanto de quem a gerou.

Ao vê-la, felicitam-na as donzelas, louvam-na as rainhas e as concubinas.

Coro.

10 Quem é esta que surge como a aurora, bela como a luz, brilhante como o sol, esplêndida como as constelações?

Ele.

11 Desci ao horto das nogueiras para examinar os brotos da várzea e ver se as vides já brotavam, se floresciam as romãzeiras.

12 Sem me aperceber, minha fantasia me transportou até às carruagens da nobre comitiva. 
A estrofe de transição, entre a primeira parte - versículos 8 e 9 - e a segunda versículos 11 e 12, está na interrogação de saber quem é a amada: "Quem é esta que surge como a aurora? (v. 10). Semelhante às mitologias antigas, quando as mulheres recebiam atributos divinos, a resposta, não poderia deixar de receber outra comparação além da própria natureza (MAZZAROLO, 2000, p.190). Ela, a amada, expressa o frescor da aurora, brilha como a luz do sol e é estonteante, indecifrável. Assemelha-se ao gesto de alguém que ousa contemplar as constelações e decifrálas.

Entre as várias mulheres, o amor se inclina somente para uma única pessoa. Há a possibilidade de relacionar a cifra de "sessenta rainhas" ao número das satrapias ou reinos transformados em pequenas províncias existentes no vasto império dos reis aquemênidas. Após Dario I (522-486 a.C.), rei Persa, a província de Judá integra a V satrapia, entregue aos cuidados do sátrapa Abar Nahara. Calcula-se em 20 o número de satrapias durante o império Persa. As satrapias eram divididas em número menor, chamadas de "províncias" (LIVERANI, 2016, p. 751). Possivelmente, a indicação numérica - sessenta, oitenta e numerosas concubinas - busque exaltar a escolha de apenas uma amada. Eis o motivo da declaração: "Um só, porém, é a minha pomba, o meu primor; única é ela para sua mãe" (v. 9).

A primavera é apresentada como a melhor época do ano para testemunhar o encontro dos jovens enamorados. Os "brotos da várzea" dão sinais ao surgimento das novas cepas e o predomínio do tom verdejante que se espalha pelo vasto e belo pomar. Não é qualquer pomar. Trata-se de um horto de nogueiras. Fruto de altíssimo valor comercial e, conforme a quantidade dos frutos colhidos, a venda seja ocasião de garantir certa segurança financeira (STADELMANN, 1993, p. 155). Em meio a um ambiente aprazível e de pura beleza natural, as fantasias acenam o êxtase no amor ao ser transportada até "às carruagens da nobre comitiva".

Coro.

7,1 Retorna, Sulamita, retorna!

Retorna, para podermos contemplar-te, retorna!

Ele.

O que vedes na Sulamita,

quando dança entre dois coros? 
2 Como são belos teus passos nas sandálias,

ó filha de príncipes!

Os contornos de teus quadris são como colares:

obra das mãos de artista.

3 Teu umbigo é uma taça redonda:

não lhe falte vinho mesclado!

Teu ventre é um monte de trigo, cercado de lírios.

4 Teus seios são como duas crias,

como gêmeos de gazela.

5 Teu pescoço é como uma torre de marfim.

Teus olhos são como as piscinas de Hesebon, junto à Porta Maior.

Teu nariz é como a torre do Líbano, sentinela sobre Damasco.

6 Tua cabeça sobressai como o Carmelo;

e as madeixas de tua cabeça são como fios de púrpura, que nos tanques um rei mantém amarrados.

Os atributos físicos da amada são realçados como prova da sua real beleza, nesta terceira parte do poema. Inquietante o modo como os versos ousam desnudar os enamorados. As declarações se alternam em meio as afirmações comprometedoras, unindo os corpos livres dos que amam por amar. A fala do amado realça a beleza de sua amada. A descrição parte dos pés e chega até os longos cabelos negros. Os pés, usando as sandálias, expressam a dureza da caminhada pelo deserto. O medo passou. Agora, os pés caminham firmes e protegidos. Os quadris e ventre referem-se aos órgãos reprodutores da mulher. Uma nova etapa está por vir. Há possibilidade de tudo recomeçar. O umbigo com a taça de vinho que transborda é o centro da vida espiritual de um mundo religioso a ser refeito. O templo deve ser reconstruído, o sacerdócio real estabelecido. No interior do templo de Jerusalém deve residir os rolos da Lei, os escritos e as profecias, um culto que evidência a justiça, o direito, como bem alerta o terceiro Isaías (Is 66,10-14).

7 Como és formosa e encantadora, 
ó delicioso amor!

8 Teu talhe assemelha-se a uma palmeira,

e teus seios a cachos.

9 Eu disse: "Vou trepar pela palmeira

e agarrar-me às suas frondes".

Teus seios devem ser como racemos na cepa,

teu hálito como a fragrância das maçãs,

10 tua boca, como vinho generoso.

Os seios, duas vezes citados no poema, descrevem o prazer ilimitado da sensualidade que envolve os jovens enamorados. A narrativa não exalta um corpo vestido, mas nu, como fora criado e posto no paraíso por Deus (Gn 2,25). Os elementos de comparação retomam outras partes do corpo. O pescoço é visto como uma torre de vigia. Não se entrava numa cidade sem ser identificado pela guarda palaciana. Os olhos não são de tristeza, mas de alegria e prazer, como as piscinas na região de Gad (Jos 21,39). A sensibilidade e certeza de pegar pelas mãos o futuro são realçadas pelo nariz, órgão que intui o discernimento e perspicácia. Não se encontra a felicidade sem ter clareza do caminho a seguir.

Os enamorados escolhem o jardim, como local apropriado para o encontro. Longe dos olhares estranhos e repreensivos, o jardim está além dos muros. Um jardim "indomesticado e exuberante não conhece outra simetria... o jardim oferece o tapete real para o desenho dos corpos dos amantes, negando toda a ideologia do puro e do impuro e toda a pretensão de monetarização dos trabalhos e dos corpos" (PEREIRA, 2006, p. 184).

Trata-se de retomar o projeto de Deus para a humanidade: viver no paraíso, onde não existe medo, violência nem exploração de alguns sobre outros. Lidos no contexto da volta do exílio (536/7 a.C.), o livro do Cântico dos Cânticos traz esperança para os deportados. Manifesta que, apesar do sofrimento, Deus comunga das dores e sonhos do seu povo.

\section{CONCLUSÃO}


Ao longo do livro do Cântico dos Cânticos, encontram-se várias comparações entre os elementos da natureza, comparados ao corpo do amado e da amada, expressando assim a força da ideia daqueles que lutam para viver um grande amor. São formas, maneiras de escrever utilizadas pelos sábios bíblicos por volta do ano 350 a.C., quando o livro recebeu sua redação final.

Há vários recursos para exaltar a beleza da amada. O uso da linguística antropológica pauta o mundo concreto, a vida das pessoas, os projetos de edificar um lugar aprazível e seguro para a convivência dos enamorados. $O$ amor não se materializa no abstrato. Olhos, cabelos, dentes, lábios, pescoço e seios acenam para a realidade jovial da amada. Os lábios e olhar são formas de expressar a sinceridade e o grau da verdade. Os seios representam a maternidade. Acenam para a realidade de segurança, de vida. É símbolo de nascimento. São jovens que se negam a fechar o amor em normas estabelecidas pelo regime patriarcal. Se contrapõem diante da teocracia. Nas sociedades antigas eram os pais que "contratavam" o casamento. Ser livre e manterse plenamente livre é o desejo dessa jovem enamorada. Busca, nada mais do que estar com aquele que a ama: "Que ele me beije" $(1,2)$. Eis seu único desejo.

Cânticos "expressa um projeto de restauração do povo na figura da mulher, a qual se torna o foco de integração do campo (as aldeias da província de Judá) e da cidade de Jerusalém. Trata-se de construir e restaurar a tese de um Povo de irmãos, que não vive na servidão e muito menos oprime seus irmãos" (Ne 5,7.18; 13,22-29) (FLORA, GORGULHO, 2006, p.337).

$\mathrm{Na}$ força desse conjunto poético, divinamente, mantido na compilação dos textos considerados Escritos, na tradição judaica, ocorrida em meados do século IV a.C., opta-se ser capaz de perceber a força que os movimentos populares, opostos aos ideais teocráticos, significaram na província persa de Yehud. A teocracia bem que tentou, mas não conseguiu inibir toda a atmosfera, a força de liberdade e amor que encontra nos jovens enamorados.

\section{REFERÊNCIAS}


BRITO, Ênio José da Costa. Leituras Afro-Brasileiras: Ressignificações afrodiaspóricas diante da condição escravizada no Brasil, São Paulo: Paco Editorial, 2018.

FRIZZO, Antonio Carlos. "Um edito" imperial e três versões de reconstruir a Yehud Persa. In: Pistis\&Praxis, Teologia e Pastoral, Curitiba, v. 12, n. 2, maio/ago. 2020, p. 206-226.

GERSTENBERGER, Erhard S. Israel no tempo dos persas. Séculos V e IV antes de Cristo. São Paulo, Loyola, 2014.

GORGULHO, Gilberto e ANDERSON, Ana Flora. O amor erótico e o projeto do povo irmão. In: DREHER, Carlos A. MUGGE, Erny. HAUENSTEIN, Iria. DREHER, Isolde R. (orgs.). Profecia e Esperança: um tributo a Milton Schwantes. São Leopoldo, Oikos, 2006, p. 337-344.

LIVERANI, Mário. Antigo Oriente: História, Sociedade e Economia, São Paulo: EDUSP, 2016.

MAZZAROLO, Isidoro. Cântico dos Cânticos: uma leitura profética do amor. Porto Alegre, Mazzarolo, 2000.

PEREIRA, Nancy Cardoso. Jardim e Poder: imperialismo persa e resistência camponesa. In: DREHER, Carlos A. MUGGE, Erny. HAUENSTEIN, Iria. DREHER, Isolde R. (orgs.). Profecia e Esperança: um tributo a Milton Schwantes. São Leopoldo, Oikos, 2006, p. 172-187.

ROSSI, Luiz Alexandre Solano. Yehud no período persa. In: Pistis\&Praxis, Teologia e Pastoral, Curitiba, v. 12, n. 2, maio/ago. 2020, p. 377-378.

STADELMANN, Luis. Cântico dos Cânticos. São Paulo: Loyola, 1993. 